\title{
Studies on the Interaction of Cefepime Hydrochloride with Bovine Serum Albumin by Fluorescence, Synchronous Fluorescence, Three-Dimensional Fluorescence and Circular Dichroism
}

\section{Daojin $\mathrm{Li}^{*}$}

College of Chemistry and Chemical Engineering, Henan Key Laboratory of Function-Oriented Porous Materials, Luoyang Normal University, Luoyang, China

\begin{abstract}
The investigation on the binding mode between drug and protein is extremely important to understand biopharmaceutics, pharmacokinetics and toxicity of the drug as well as the relationship of structure and function of the protein. It is well proved that biological activity is a function of the chemical structure or structural properties. There is a study on the interaction of cefepime hydrochloride with serum albumin using in-silico molecular docking. But up to date, there is hardly any interaction investigation of cefepime hydrochloride with serum albumin utilizing by fluorescence, synchronous fluorescence, three-dimensional fluorescence and circular dichroism. In this study, the interaction of cefepime hydrochloride with bovine serum albumin in aqueous solution has been investigated by molecular spectroscopy under different $\mathrm{pH}$ conditions. The quenching rate constant and binding constant calculated at $\mathrm{pH} 7.4$ indicated the static quenching mechanism and medium binding force. The effect of cefepime hydrochloride on the conformation of bovine serum albumin was analyzed using fluorescence, synchronous fluorescence, threedimensional fluorescence and circular dichroism. In addition, influence of $\mathrm{pH}$ on the binding of cefepime hydrochloride to bovine serum albumin was investigated and the binding ability of the drug to bovine serum albumin deceased

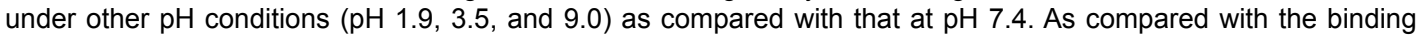
ability of cefepime hydrochloride to native bovine serum albumin that of cefepime hydrochloride to denatured bovine serum albumin deceases dramatically. Furthermore, the effect of metal ions on the binding constant of cefepime hydrochloride with bovine serum albumin was investigated.
\end{abstract}

Keywords: Cefepime hydrochloride; Bovine serum albumin; Fluorescence quenching; Circular dichroism; Three-dimensional fluorescence

\section{Introduction}

The interaction of proteins with drugs has attracted great interest among researchers for many years [1-3]. Serum Albumin (SA), the most important transport protein, has been frequently used as a model protein for investigating the protein folding and ligand-binding mechanism. In this regard, Bovine Serum Albumin (BSA) has been extensively studied, partly due to its structural homology with Human Serum Albumin (HSA) [4-8]. BSA (Figure 1), composed of three linearly arranged,

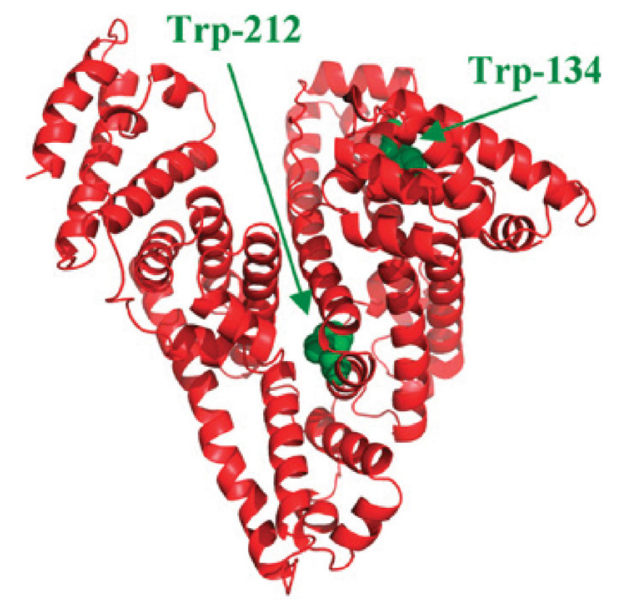

Figure 1: Structure of bovine serum albumin, with Tryptophan residues shown in green color. structurally homologous sub-domains (A, B), has two tryptophan residues Trp-134, which is located on the surface of sub-domain IB, and Trp-212, locating within the hydrophobic binding pocket of subdomain IIA [9]. The principal regions of drugs binding sites of SA are often located in hydrophobic cavities in sub-domains IIA and IIIA.

Cefepime hydrochloride (Figure 2) is a type of broad spectrum fourth-generation cephalosporin antibiotic. It has good antimicrobial activity against Gram-negative bacteria, including Enterobacter spp., Klebsiella pneumoniae, Escherichia coli, Pseudomonas aeruginosa, and Staphylococcus bacteria grapes. It is more active against some Gram-positive bacteria, such as Streptococcus pyogenes, Streptococcus pneumoniae compared with the three-generation cephalosporin [10].

In addition, investigation on the interaction between drug and protein under various $\mathrm{pH}$ conditions would provide information for profoundly understanding the pharmacological actions of the drug and the relationships of their structures and functions [11]. The binding affinity of drug with protein may be weaker when $\mathrm{pH}$-induced conformational changes of the protein occurs [11], which would directly

*Corresponding authors: Daojin Li, College of Chemistry and Chemical Engineering, Henan Key Laboratory of Function-Oriented Porous Materials, Luoyang Normal University, Luoyang, China, Tel: +862583685639; E-mail: lidaojin7910@163.com

Received March 08, 2017; Accepted April 11, 2017; Published April 19, 2017

Citation: Li D (2017) Studies on the Interaction of Cefepime Hydrochloride with Bovine Serum Albumin by Fluorescence, Synchronous Fluorescence, ThreeDimensional Fluorescence and Circular Dichroism. J Bioanal Biomed 9: 107-113. doi:10.4172/1948-593X.1000162

Copyright: @ 2017 Li D. This is an open-access article distributed under the terms of the Creative Commons Attribution License, which permits unrestricted use, distribution, and reproduction in any medium, provided the original author and source are credited. 
<smiles>CO/N=C(\C(=O)N[C@H]1C(=O)N2C(C(=O)O)=C(C[N+]3(C)CCCC3)CS[C@H]12)c1csc(N)n1</smiles>

Figure 2: Chemical structure of cefepime hydrochloride.

influence the concentration of drug in the blood. Thus, the biological actions of the drug can be affected. It is necessary to investigate the interaction of drug with BSA under different $\mathrm{pH}$ conditions.

Furthermore, weaker interaction of drug with denatured BSA can lead to obvious increase of drug concentration in the blood. Sometimes this effect may cause toxic poisoning or even cause death [12]. Therefore, studies on the binding of drug to denatured BSA can improve interpretation of the metabolism and transporting process of drug, which is extremely helpful to understand the relationship between the structure and the function of the protein.

Moreover, there are also some metal ions present in blood, which can affect the binding of the drugs with protein [13]. They could participate in many biochemical processes. Some proteins have a variety of metal sites and metal ions-BSA binding can cause conformational alteration of BSA. So it can be deduced that metal ions may have obvious effect on the interaction of medicine molecules with BSA, and thus it would influence the distribution, pharmacological property, and metabolism of drug in blood.

Due to great importance on the binding study of drugs with proteins in pharmacy, pharmacology and biochemistry, our group has made many efforts in this direction in current years [13-24]. The interaction between BSA and several small molecules, such as baicalein [13], farrerol [18], B12 [19], rutin [20], cinchonidine [21] and nevadensin [24] have been investigated in recent years. However, to date, there is no report on the binding of cefepime hydrochloride to BSA, especially on the effect of $\mathrm{pH}$, urea and metal ions on the interaction of cefepime hydrochloride with BSA.

In this study, the interaction of cefepime hydrochloride with BSA reported was reported at physiological $\mathrm{pH}$ conditions. The static fluorescence quenching mechanism and medium binding constant was presented and the conformational change of BSA induced by cefepime hydrochloride was investigated using fluorescence and $\mathrm{CD}$. In addition, influences of $\mathrm{pH}$, urea and metal ions on the interaction of cefepime hydrochloride with BSA were systemically investigated by steady state fluorescence.

\section{Materials and Methods}

\section{Materials and preparation of solutions}

BSA was purchased from Sigma (USA). Cefepime hydrochloride was of analytical grade, and purchased from Sinopharm Group Chemical Reagent Co., Ltd. (China). All other reagents were of analytical grade. Double-distilled water was used throughout experiments. The $\mathrm{pH}$ of the phosphate buffer solution $(20 \mathrm{mmol} / \mathrm{L})$ was adjusted to $1.9,3.5,7.4$ and 9.0. The concentration of BSA in the buffer was prepared using 66.5 $\mathrm{kDa}$ as molecular weight, and the final concentration was checked by measuring absorbance with the published value (optical absorbance at $280 \mathrm{~nm}) 0.531(1 \mathrm{~g} / \mathrm{L})$. The stock solution $\left(2 \times 10^{-3} \mathrm{~mol} / \mathrm{L}\right)$ of cefepime hydrochloride was prepared by dissolving appropriate amount of cefepime hydrochloride in $10 \mathrm{~mL}$ anhydrous methanol. For the determination of fluorescence quenching, the quenching rate constants, and binding constants, the concentration of BSA was $4 \mu \mathrm{M}$. The molar ratio of metal ions to BSA was 1. Metal chlorides were used in the metal ion binding effect studies.

\section{Apparatus and methods}

Fluorescence measurements were performed on an F-4500 spectrofluorophotometer (Hitachi, Japan) equipped with $1.0 \mathrm{~cm}$ quartz cells following an excitation at $295 \mathrm{~nm}$. The widths of both the excitation slit and the emission slit were adjusted at $5 \mathrm{~nm}$. The three-dimensional fluorescence spectra were performed under the following conditions: the emission wavelength scan range was recorded between $240 \mathrm{~nm}$ and $440 \mathrm{~nm}$ at $1 \mathrm{~nm}$ increments, and the excitation wavelength scan range was recorded from 200 to $360 \mathrm{~nm}$ at $5 \mathrm{~nm}$ increments. The number of scanning curves was 34 , and the excitation and emission bandwidths were $5 \mathrm{~nm}$. CD spectral measurements were run on an Olis DSM 1000 automatic recording spectrophotometer in a $1 \mathrm{~mm}$ cell

A $3 \mathrm{~mL}$ buffer solution, containing appropriate concentration of BSA under different $\mathrm{pH}$ conditions was titrated by successive additions of a $2 \mathrm{mM}$ solution of cefepime hydrochloride. Titrations were performed manually by using trace syringes. The effects of metal ions on the interaction of cefepime hydrochloride with BSA were investigated by the gradual addition of cefepime hydrochloride to the mixture of metal ions and BSA.

\section{Results and Discussion}

\section{Binding mechanisms of cefepime hydrochloride with bovine serum albumin}

Fluorescence of BSA originates from Tryptophan (Trp), Tyrosine (Tyr) and Phenylalanine (Phe) residues. Because the Phe residue has a relatively low quantum yield and the fluorescence of Tyr is almost totally quenched by nearby an amino group, a carboxyl group, or a Trp [25], the intrinsic fluorescence of BSA is mainly contributed by the Trp residue alone.

Figure 3 showed the fluorescence emission spectra of native BSA with various amount of cefepime hydrochloride at the excitation wavelength of $295 \mathrm{~nm}$. It could be observed that the fluorescence intensity decreases regularly with the increase of cefepime hydrochloride concentration, indicating that the fluorescence quenching mechanism may be rationalized in terms of a static quenching process.

To confirm the quenching mechanism induced by cefepime hydrochloride, fluorescence quenching data are analyzed with the Stern-Volmer equation (Equation 1) [26-37]:

$$
\frac{F_{0}}{F}=1+k_{q} \tau_{0}[Q]=1+K_{S V}[Q]
$$

where $F_{0}$ and $F$ are the relative fluorescence intensities in the absence and presence of quencher, respectively, $[Q]$ the concentration of quencher, $k_{\mathrm{q}}$ the biomolecular quenching rate constant, $\tau_{0}$ the average bimolecular life-time in the absence of quencher evaluated at about $5 \mathrm{~ns}$ [26] and $K_{S V}$ the Stern-Volmer dynamic quenching constant that was determined by linear regression of a plot of $F_{0} / F$ against [Q]. A plot of $F_{0} / F$ versus $[Q]$ was shown in Figure 4 . The values for $K_{S V}$ and $k_{q}$ are presented in Table 1 . The calculated $k_{\mathrm{q}}$ value is greater than the maximum dynamic 


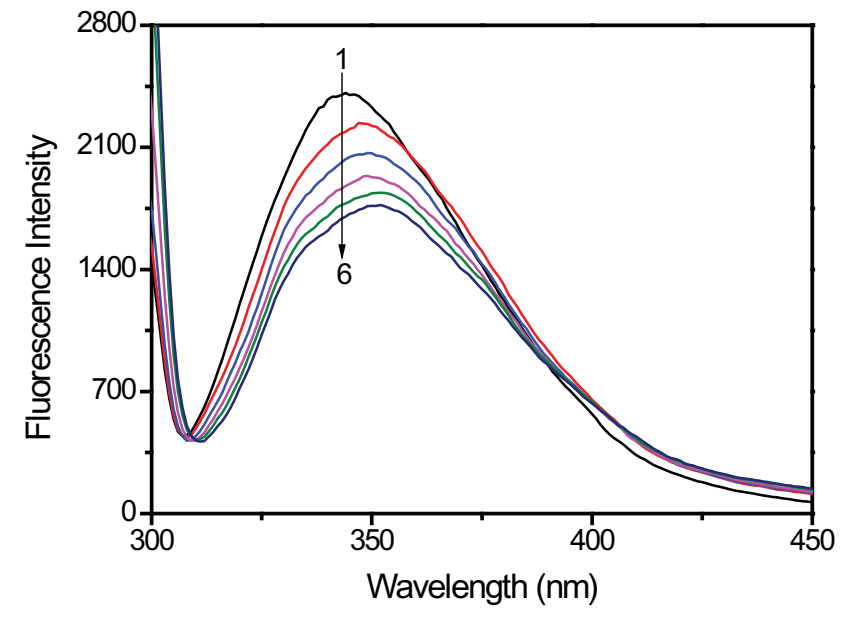

Figure 3: Fluorescence emission spectra of bovine serum albumin in the presence of various concentrations of cefepime hydrochloride at $\mathrm{pH}$ 7.4. (1-6) The concentrations of cefepime hydrochloride are $(\mu \mathrm{M}): 0,4,12,20,28$ and 36; [bovine serum albumin] $=4 \mu \mathrm{M} ; \lambda_{\mathrm{ex}}=295 \mathrm{~nm}$.

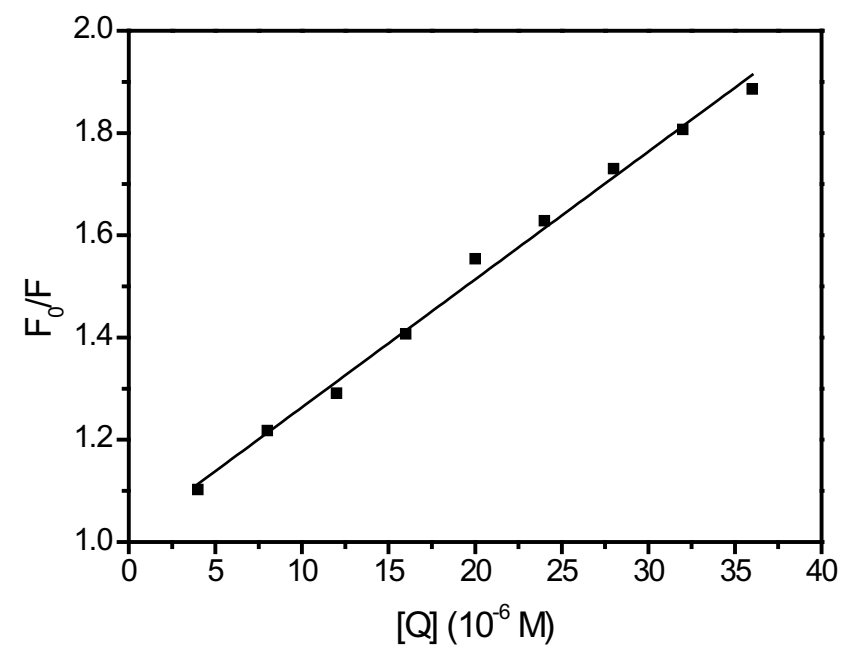

Figure 4: Plots of $F_{0} / F$ for bovine serum albumin against cefepime hydrochloride concentration ranging from 4 to $36 \mu \mathrm{M}$; [bovine serum albumin] $=4 \mu \mathrm{M}$.

\begin{tabular}{|c|c|c|c|c|c|c|c|}
\hline $\mathbf{p H}$ & Lys state & $\begin{array}{c}\boldsymbol{K}\left(\mathbf{\times 1 0 ^ { 4 }} \mathbf{L} \mathbf{l}\right. \\
\mathbf{m o l})\end{array}$ & $\boldsymbol{n}$ & $\boldsymbol{R}$ & $\begin{array}{c}\boldsymbol{K}_{\text {sv }}\left(\mathbf{\times 1 0 ^ { 4 }} \mathbf{L} /\right. \\
\mathbf{m o l})\end{array}$ & $\begin{array}{c}\boldsymbol{k}_{q}\left(\times \mathbf{1 0}^{12} \mathbf{L} /\right. \\
\mathbf{m o l} / \mathbf{s})\end{array}$ & $\boldsymbol{R}$ \\
\hline \multirow{2}{*}{7.4} & Native & 2.36 & 0.99 & 0.998 & 2.50 & 5.00 & 0.997 \\
\cline { 2 - 8 } & Denatured & 0.10 & 0.79 & 0.999 & 0.76 & 1.52 & 0.996 \\
\hline \multirow{2}{*}{1.9} & Native & 0.10 & 0.80 & 0.997 & - & - & - \\
3.5 & Native & 0.72 & 0.93 & 0.992 & & & \\
\hline 9.0 & Native & 1.38 & 0.79 & 0.994 & - & - & - \\
\hline
\end{tabular}

Table 1: Fluorescence quenching constant and binding constant of bovine serum albumin-cefepime hydrochloride system under different $\mathrm{pH}$ conditions.

collisional quenching constant $\left(2.0 \times 10^{10} \mathrm{~L} \mathrm{~mol}^{-1} \mathrm{~s}^{-1}\right)$ of quenchers with biopolymers $[38,39]$. The result implies that the fluorescence quenching was controlled by a static quenching mechanism.

For the static quenching process, the equilibrium between free and bound molecule is given by the following equation (Equation 2) [40,41]:

$$
\log \frac{\left(F_{0}-F\right)}{F}=\log K+n \log [Q]
$$

Where $K$ is the binding constant and $n$ the number of binding sites. The values for $K$ and $n$ can be calculated by a plot of $\log \left(F_{0}-F\right) / F$ versus $\log [Q]$ (Figure 5) and presented in Table 1. The value of $n$ indicates that one molecule of BSA combined with one molecule of the drug. The values for $K$ and $n$ indicated that cefepime hydrochloride was able to bind to BSA via medium binding force.

\section{Effect of cefepime hydrochloride on the conformation of bovine serum albumin}

Fluorescence and synchronous fluorescence spectroscopic studies of bovine serum albumin: In addition to the proximity of bound cefepime hydrochloride to Trp residue, fluorescence quenching might result from structural change of BSA upon cefepime hydrochloride binding [42]. As is well known, the maximum fluorescence emission wavelength $\left(\lambda_{\mathrm{em}}\right)$ of Trp residues is closely related to the polarity of the microenvironment around Trp residues. Therefore, the changes in $\lambda_{\mathrm{em}}$ of BSA will reflect the conformation changes of BSA. It was observed from Figure 3 that $\lambda_{\mathrm{em}}$ of BSA shifted from $343 \mathrm{~nm}$ to 351 $\mathrm{nm}$ after the addition of cefepime hydrochloride. It implies that the interaction of cefepime hydrochloride with BSA resulted in a significant conformational change of Trp residues micro-regions.

In addition, the change of BSA conformation upon addition of cefepime hydrochloride can be also demonstrated by synchronous fluorescence spectra. As is known, synchronous fluorescence spectroscopy is a very useful method to investigate the microenvironment of amino acid residues by measuring the emission wavelength $[43,44]$ and has several advantages such as sensitivity, spectral simplification, and spectral bandwidth reduction [45].

As is known, synchronous fluorescence spectra show Trp residues of BSA only at the wavelength interval $(\Delta \lambda)$ of $60 \mathrm{~nm}$ and Tyr residues of BSA only at $\Delta \lambda$ of $15 \mathrm{~nm}$. As such, Figure $6 \mathrm{~A}$ and $6 \mathrm{~B}$ showed the effect of cefepime hydrochloride on the synchronous fluorescence spectra of Trp and Tyr residues in BSA, respectively. It can be observed from Figure 6 that emission maximum of Trp residues was red shifted while the emission maximum of Tyr residues kept constant at the investigated concentrations range. It indicated that the polarity around tryptophan residues increased, which suggested that tryptophan residues were

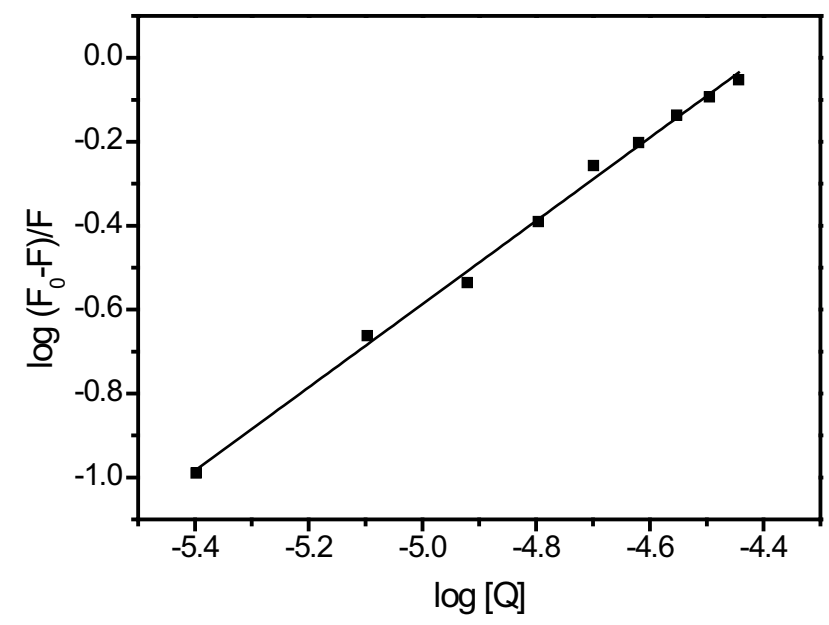

Figure 5: Plot of log $\left(F_{0}-F\right) / F$ for bovine serum albumin vs. log [Q] [bovine serum albumin] $=4 \mu \mathrm{M}$. 

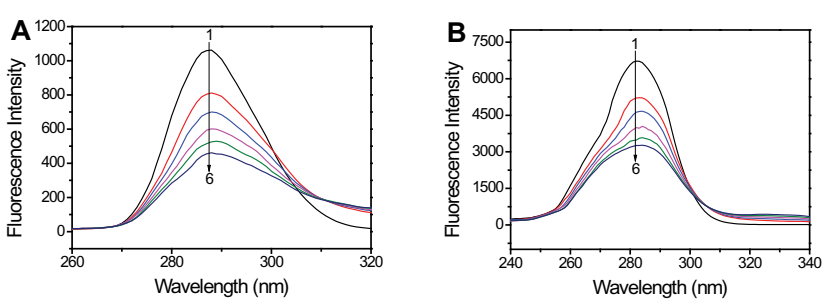

Figure 6: Synchronous fluorescence spectra of bovine serum albumin with various amounts of cefepime hydrochloride. (1-6) The concentrations of cefepime hydrochloride are $(\mu \mathrm{M}): 0,4,12,20,28$ and 36 ; [bovine serum albumin] $=4 \mu \mathrm{M} ;(\mathrm{A}): \Delta \lambda=15 \mathrm{~nm}$ and $(\mathrm{B}): \Delta \lambda=60 \mathrm{~nm}$.

located in a less hydrophobic environment. It implies that the interaction of cefepime hydrochloride with BSA led to a conformational change of Trp residues micro-regions while it did not affect significantly the conformational change around Tyr residues micro regions.

Three-dimensional fluorescence spectroscopic studies: Threedimensional fluorescence is a popular fluorescence analysis technique in current years [46] since the three-dimensional fluorescence spectrum can provide more detailed information on the change of the configuration of proteins. In addition, the contour map can also provide much important information. Figure 7 showed the three-dimensional fluorescence spectra and contour ones of BSA or cefepime hydrochloride-BSA. Two typical fluorescence peaks (peak 1 and peak 2) of BSA with a variety of cefepime hydrochloride could be observed in isometric three-dimensional projection or threedimensional fluorescence contour map. As depicted in Figure 7, peak 1 mainly reveals the spectral characteristic of tryptophan and tyrosine residues. The fluorescence intensity of the peak decreased and the maximum emission wavelength resulted in red shift after the addition of cefepime hydrochloride (Table 2). This red shift effect indicates that conformational changes of BSA occurred since red shift led to the increase of the polarity around the Trp residues, which was in good agreement with the result obtained from fluorescence and synchronous fluorescence spectroscopy.

The excitation wavelength of peak 2 is $235 \mathrm{~nm}$, being related to the conformation of the peptide backbone associated with the helix-coil. The emission intensity of BSA decreased and the emission wavelength has a little red shift upon addition of cefepime hydrochloride, which implied that the interaction of cefepime hydrochloride with BSA changed the polypeptide backbone structures of BSA.

Circular dichroism spectroscopic studies: $C D$ is a sensitive technique to investigate the conformational changes of proteins upon the interaction with a ligand. Figure 8 displays the CD spectra of BSA before and after the addition of cefepime hydrochloride. They exhibit two negative bands at $209 \mathrm{~nm}$ and $222 \mathrm{~nm}$, which is a typical characteristic of the $\alpha$-helix structure of proteins [47]. As we know, the solvent used for CD studies has no CD signa. The negative bands at 208 $\mathrm{nm}$ and $222 \mathrm{~nm}$ are contributed by the $\mathrm{n} \rightarrow \pi^{*}$ transition in the peptide bond [48]. It can be observed that there was an apparent reduction in both bands without any significant shift of the peaks, which implied that binding of cefepime hydrochloride to BSA causes a conformational change of the protein.

\section{Influence of $\mathrm{pH}$ on the interaction of cefepime hydrochloride with bovine serum albumin}

It is well known that the fluorescence of BSA is related to $\mathrm{pH}$ in
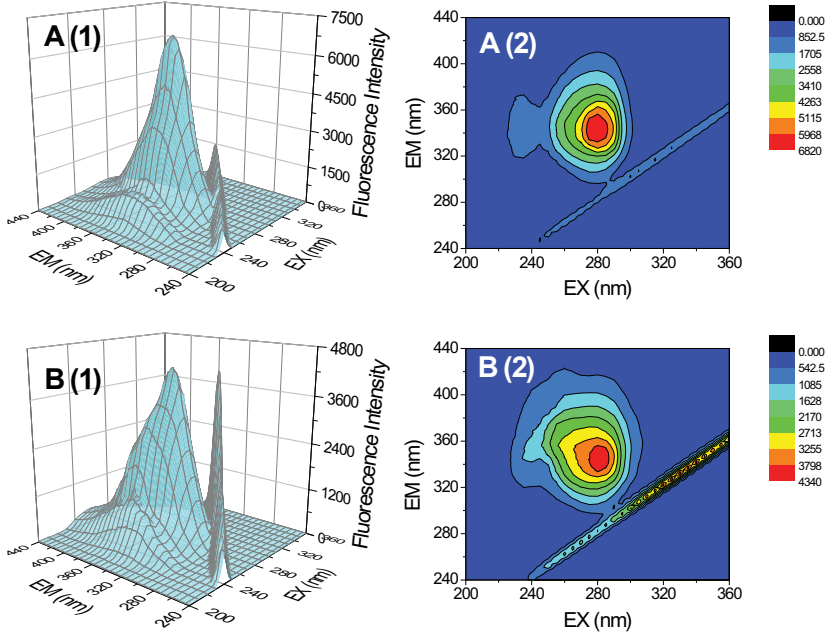

Figure 7: The three-dimensional fluorescence projections and threedimensional fluorescence contour map of bovine serum albumin before $(A)$ and after (B) cefepime hydrochloride addition. (A): [bovine serum albumin]=4 $\mu \mathrm{M}$; (B): [bovine serum albumin] $=4 \mu \mathrm{M}$; [Cefepime hydrochloride $]=16 \mu \mathrm{M}$.

\begin{tabular}{|l|l|c|c|}
\hline System & Peak 1 & Peak 2 \\
\hline BSA & Peak position & $280 / 342$ & $235 / 343$ \\
& Relative intensity, F & 6807 & 1237 \\
\hline Cefepime hydrochloride/BSA (4:1) & Peak position & $280 / 345$ & $235 / 344$ \\
& Relative intensity, F & 4975 & 862.8 \\
\hline
\end{tabular}

Table 2: Three-dimensional fluorescence characteristics of bovine serum albumin and bovine serum albumin-cefepime hydrochloride system at $\mathrm{pH} 7.4$.

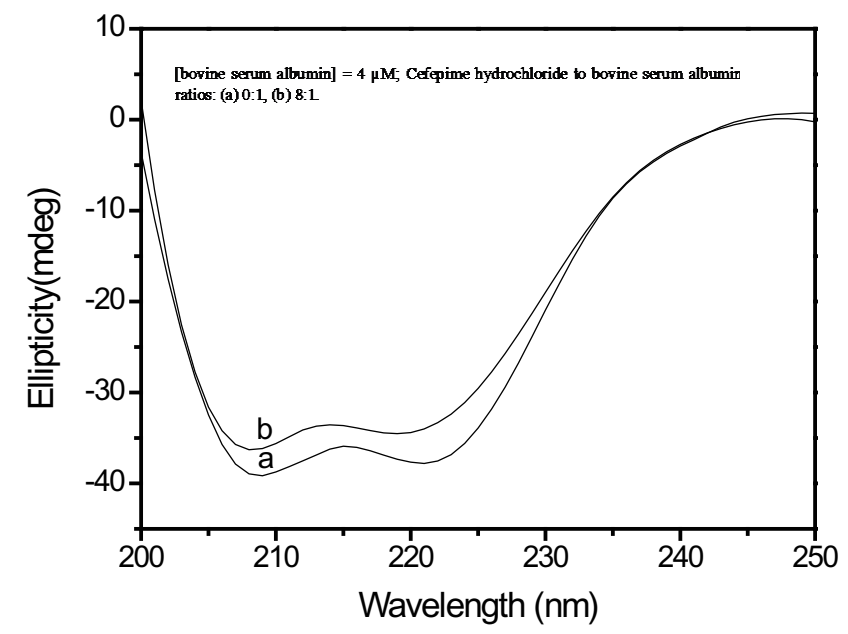

Figure 8: Circular dichroism spectra of the cefepime hydrochloride-bovine serum albumin system at $\mathrm{pH} 7.40$ at $298 \mathrm{~K}$. [bovine serum albumin] $=4 \mu \mathrm{M}$; Cefepime hydrochloride to bovine serum albumin ratios: (a) 0:1, (b) 8:1.

buffer solutions since $\mathrm{pH}$ has obvious effect on the conformation of the protein. Thus, $\mathrm{pH}$ may affect the interaction of between drugs and BSA. In order to explore the influence of $\mathrm{pH}$ on the cefepime hydrochlorideBSA interaction, the fluorescence quenching data of BSA without and with cefepime hydrochloride $\left(\mathrm{C}_{\text {cefepime hydrochloride }} / \mathrm{C}_{\mathrm{BSA}}=1,4\right.$ and 8 , respectively) was analyzed under different $\mathrm{pH}$ conditions (Figure 9). A fluorescence quenching fraction $Q$ was defined as follow:

$$
Q=\left(F_{0}-F\right) / F_{0} \times 100 \%
$$


Citation: Li D (2017) Studies on the Interaction of Cefepime Hydrochloride with Bovine Serum Albumin by Fluorescence, Synchronous Fluorescence, Three-Dimensional Fluorescence and Circular Dichroism. J Bioanal Biomed 9: 107-113. doi:10.4172/1948-593X.1000162

Where $F_{0}$ and $F$ represent the relative fluorescence intensities of BSA before and after binding of cefepime hydrochloride to BSA under various $\mathrm{pH}$ conditions. Clearly, the extent of the fluorescence quenching can be well reflected using $Q$. Figure 9 shows the effect of $\mathrm{pH}$ on the fluorescence quenching fractions of BSA induced by cefepime hydrochloride at the molar ratio of the drug to protein was 1 , 4 and 8 , respectively. It was observed that the fluorescence quenching extent at $\mathrm{pH} 7.4$ is the greatest in all the four $\mathrm{pHs}$, which implies that the binding affinity of BSA for cefepime hydrochloride at $\mathrm{pH} 7.4$ may be greater than that at the other pHs. This result can be successfully confirmed by the determination of binding constant $(K)$ of cefepime hydrochloride with BSA under four different $\mathrm{pH}$ conditions (Figure 10). The values for $K$ at $\mathrm{pH} 1.9,3.5,7.4$ and 9.0 are also listed in Table 1 , which indicated that BSA indeed exhibited the highest binding force toward cefepime hydrochloride at $\mathrm{pH}$ 7.4. This phenomenon may result from two aspects, protein and drug. As depicted in Figure 11, the

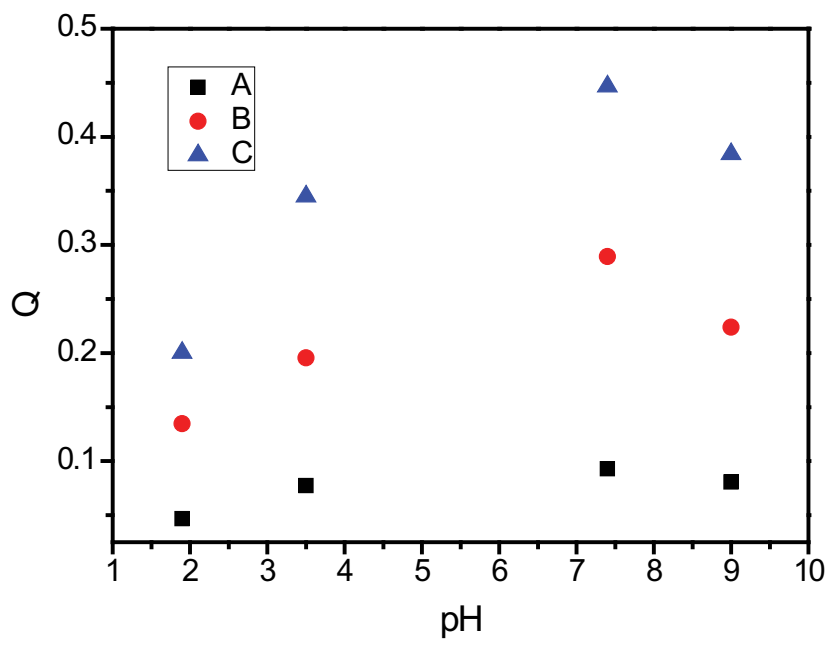

Figure 9: The effect of $\mathrm{pH}$ on the fluorescence quenching fractions $Q$ of bovine serum albumin induced by cefepime hydrochloride: $(A)$ the drug to protein molar ratio is $1,(B)$ the drug to protein molar ratio is $4,(C)$ the drug to protein molar ratio is 8 .

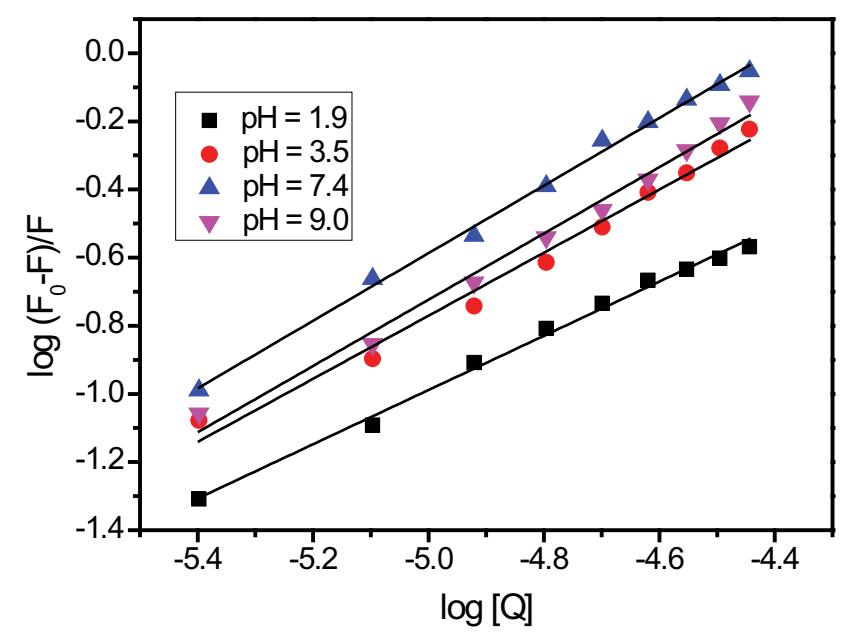

Figure 10: Plots of $\log \left(F_{0}-F\right) / F$ for bovine serum albumin vs. log [Q] under different $\mathrm{pH}$ conditions; [bovine serum albumin] $=4 \mu \mathrm{M}$. maximum emission wavelengths of BSA shift from 343 to $335 \mathrm{~nm}$ and $338 \mathrm{~nm}$ when $\mathrm{pH} 7.4$ changes into 3.5 and 1.9 , respectively. In addition, the fluorescence intensity of BSA was greater than that at $\mathrm{pH} 1.9,3.5$, or 9.0. The above results indicate that the influence of $\mathrm{pH}$ on the structure of BSA is relatively great, thus impacting binding capacity of drug to BSA [49,50]. Moreover, the drug may be a little sensitive to the $\mathrm{pH}$ because it would cause different concentration of ionization state. Thus, the binding ability of drug to BSA would be affected.

\section{The interaction of urea-induced bovine serum albumin with cefepime hydrochloride}

The denaturation of protein can be induced chemically by using urea, SDS, or acetone, etc. [38]. As is well known, higher than $8 \mathrm{M}$ urea would lead to the complete denaturation of BSA [21]. To explore the interaction of completely denatured BSA caused by urea with cefepime hydrochloride, we investigated the fluorescence of denatured BSA with various amount of cefepime hydrochloride. The values for

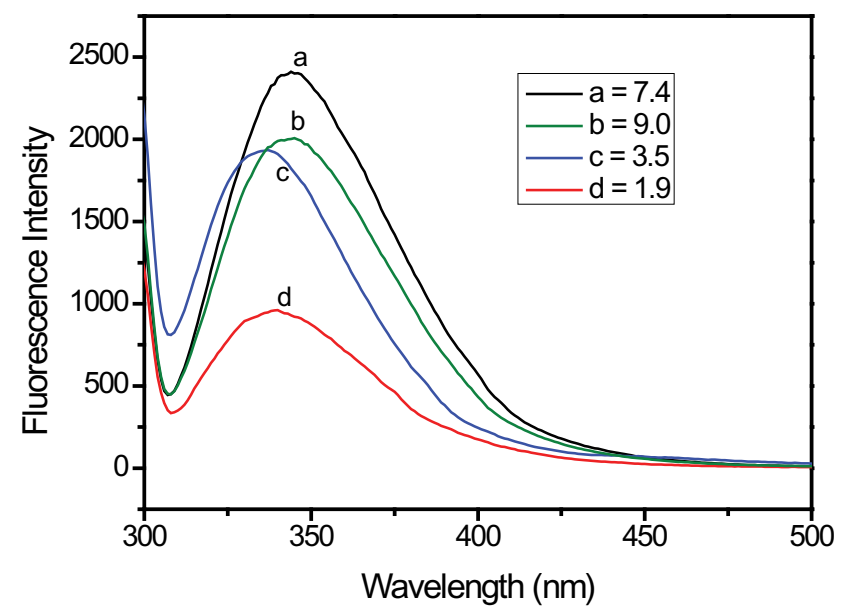

Figure 11: Fluorescence emission spectra of bovine serum albumin in different pHs: (a) 7.4, (b) 9.0, (c) 3.5, and (d) 1.9; [bovine serum albumin] $=4.0 \mu \mathrm{M}$.

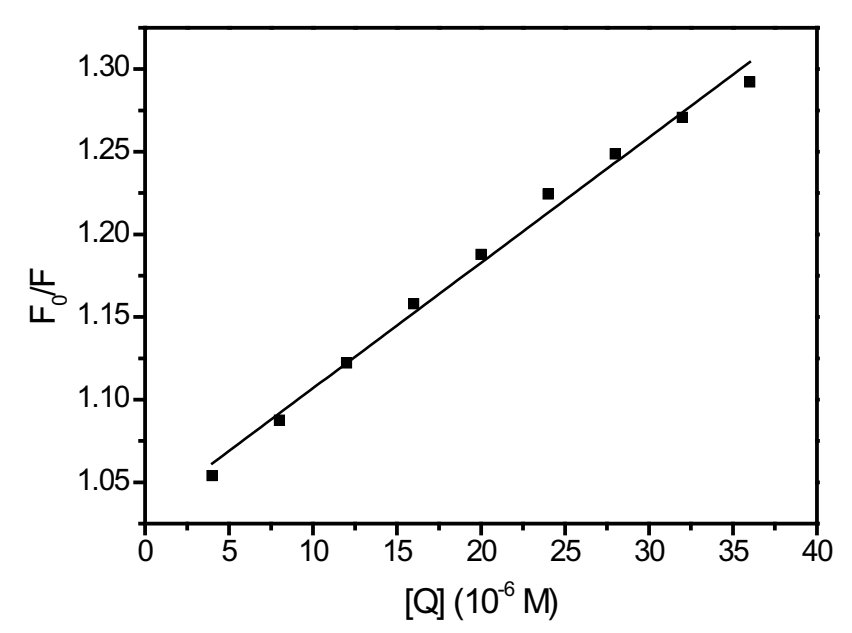

Figure 12: Plot of $F / F$ for denatured bovine serum albumin against [Q] of cefepime hydrochloride ranging from 4 to $36 \mu \mathrm{M}$ under different $\mathrm{pH}$ conditions; [bovine serum albumin] $=4 \mu \mathrm{M}$. 
$K_{S V}$ and $k_{q}$ were determined by linear regression curve (Figure 12) of $F_{0} / F$ for against $[Q]$ and presented in Table 1 . This result indicates that the fluorescence quenching process of denatured BSA by cefepime hydrochloride was also controlled by a static quenching mechanism arising from a complex formation.

In addition, we evaluated the binding constant of cefepime hydrochloride with denatured BSA, which was plotted by $\log \left(F_{0} / F\right) / F$ versus $\log [Q]$ based on equation 2 as shown in Figure 13 and the corresponding value was listed in Table 1 . It can be observed that the binding ability of denatured BSA with cefepime hydrochloride decreased as compared with that of native BSA. It implied that the binding drug in the hydrophobic pocket in the native BSA was partially removed during denaturation [51].

\section{Influence of metal ions on the binding content of cefepime hydrochloride with bovine serum albumin}

Metal ions are vital to human body and play important role on many proteins. The presence of metal ions in blood may affect interaction of drugs with BSA. The effect of metal ions on the binding constant $K$ of cefepime hydrochloride-BSA complex were investigated at pH 7.4 and the values for $K$ were presented in Table 3. Obviously, the presence of $\mathrm{Al}^{3+}, \mathrm{Mg}^{2+}, \mathrm{Ca}^{2+}$ or $\mathrm{K}^{+}$reduced the cefepime hydrochloride-BSA binding, which may result from the competition of binding of metal ions and cefepime hydrochloride to BSA in the same binding site. The presence of metal ions reduces the cefepime hydrochloride-BSA binding, causing cefepime hydrochloride to be quickly cleared from the body, which may lead to the need for more doses of cefepime hydrochloride to achieve the desired medicinal effect. However, in case of $\mathrm{Zn}^{2+}$ or $\mathrm{Fe}^{3+}$, the binding constant of cefepime hydrochloride-BSA

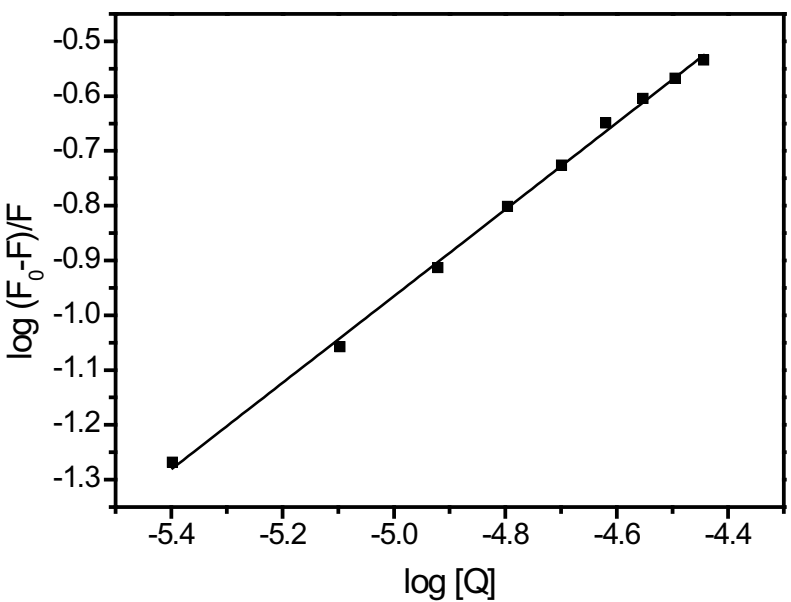

Figure 13: Plot of $\log \left(F_{0}-F\right) / F$ vs. log [Q] for denatured bovine serum albumin/ cefepime hydrochloride system; [bovine serum albumin] $=4 \mu \mathrm{M}$.

\begin{tabular}{|c|c|c|c|c|}
\hline Metal ions & $\boldsymbol{K}^{\prime}(\mathbf{\times} \mathbf{1 0} \mathbf{~} \mathbf{/ m o l})$ & $\boldsymbol{n}$ & $\boldsymbol{R}$ & $\boldsymbol{K} \mathbf{\prime}^{\prime} \mathbf{K}$ \\
\hline $\mathrm{Al}^{3+}$ & 1.14 & 0.89 & 0.993 & 0.483 \\
\hline $\mathrm{Mg}^{2+}$ & 1.81 & 0.96 & 0.997 & 0.767 \\
\hline $\mathrm{Zn}^{2+}$ & 5.94 & 1.08 & 0.996 & 2.52 \\
\hline $\mathrm{Ca}^{2+}$ & 0.356 & 0.86 & 0.994 & 0.151 \\
\hline $\mathrm{K}^{+}$ & 1.67 & 0.97 & 0.992 & 0.708 \\
\hline $\mathrm{Fe}^{3+}$ & 8.79 & 1.13 & 0.994 & 3.72 \\
\hline
\end{tabular}

Table 3: Effects of metal ions on binding constants of cefepime hydrochloridebovine serum albumin. increased a conformational change in BSA, being more favorable for cefepime hydrochloride binding to BSA. Thus, the increase in binding constant of cefepime hydrochloride-BSA in presence of the above ions prolongs storage compared with that without these ions. The higher binding constant may result from the fact that $\mathrm{Zn}^{2+}$ or $\mathrm{Fe}^{3+}$ induced period of cefepime hydrochloride in blood and weaken its maximum medicinal effects.

\section{Conclusion}

In the paper, influences of $\mathrm{pH}$, urea, and metal ions on the interaction of cefepime hydrochloride with BSA were characterized by molecular spectroscopy. It can be elicited that the binding reaction of cefepime hydrochloride with the protein in blood is sensitive to the change in $\mathrm{pH}$. The $\mathrm{pH} 7.4$ is the optimal acidity. In addition, the denatured BSA resulted in weaker binding affinity of the protein towards cefepime hydrochloride. The effect of metal ions on the binding constant of cefepime hydrochloride with BSA was studied. This study can also provide important insight into the interactions of the physiologically important protein with drugs. This study will be also helpful to structure-based drug design.

\section{References}

1. Kandagal PB, Ashoka S, Seetharamappa J, Shaikh SMT, Jadegoud Y, et al (2006) Study of the interaction of an anticancer drug with human and bovine serum albumin: Spectroscopic approach. J Pharm Biomed Anal 41: 393-399.

2. Zhu X, Sun J, Hu Y (2007) Determination of protein by hydroxypropyl-betacyclodextrin sensitized fluorescence quenching method with erythrosine sodium as a fluorescence probe. Anal Chim Acta 596: 298-302.

3. Wang YQ, Zhang HM, Zhang GC (2006) Studies of the interaction between palmatine hydrochloride and human serum albumin by fluorescence quenching method. J Pharm Biomed Anal 41: 1041-1046.

4. Wang YQ, Zhang HM, Zhang GC, Tao WH, Fei ZH, et al. (2007) Spectroscopic studies on the interaction between silicotungstic acid and bovine serum albumin. J Pharm Biomed Anal 43: 1869-1875.

5. Zhou N, Liang YZ, Wang PJ (2007) 18ß-Glycyrrhetinic acid interaction with bovine serum albumin. Photochem Photobiol A 185: 271-276.

6. Bertucci C, Cimitan S, Riva A, Morazzoni P (2006) Binding studies of taxanes to human serum albumin by bioaffinity chromatography and circular dichroism. J Pharm Biomed Anal 42: 81-87.

7. Hu YJ, Liu Y, Zhao RM, Dong JX, Qu SS (2006) Spectroscopic studies on the interaction between methylene blue and bovine serum albumin. J Photochem Photobiol A Chem 179: 324-329.

8. Wang YP, Wei YL, Dong C (2006) Study on the interaction of 3,3-bis(4-hydroxy1-naphthyl)-phthalide with bovine serum albumin by fluorescence spectroscopy. J Photochem Photobiol A 177: 6-11.

9. Anbazhagan V, Renganathan R (2008) Study on the binding of 2,3-diazabicyclo[2.2. 2]oct-2-ene with bovine serum albumin by fluorescence spectroscopy. J Lumin 128: 1454-1458.

10. Dabrowska M, Starek M, Krzek J (2015) A degradation study of cefepime hydrochloride in solutions under various stress conditions by TLC-densitometry. Biomed Chromatogra 29: 388-396.

11. Ahmad B, Parveen S, Khan RH (2006) Effect of albumin conformation on the binding of ciprofloxacin to human serum albumin: a novel approach directly assigning binding site. Biomacromolecules 7: 1350-1356.

12. Rownicka J, Sulkowska A, Pozycka J, Bojko B, Sulkowski WW (2006) Stability of the complex BSA-6-propyl-2-thiouracil in the presence of $\mathrm{Gu} \mathrm{HCl}$ and urea. J Mol Struct 792-793: 243-248.

13. Li D, Zhu M, Xu C, Ji B (2011) Characterization of the Baicalein-Bovine Serum Albumin Complex Without or With $\mathrm{Cu}^{2+}$ or $\mathrm{Fe}^{3+}$ by Spectroscopic Approaches. Eur J Med Chem 46:588-599.

14. Li D, Yang YM, Cao XX, Xu C, Ji B (2012) Investigation on the pH-dependent binding of vitamin B12 and lysozyme by fluorescence and absorbance. J Mo Struct 1007: 102-112. 
Citation: Li D (2017) Studies on the Interaction of Cefepime Hydrochloride with Bovine Serum Albumin by Fluorescence, Synchronous Fluorescence, Three-Dimensional Fluorescence and Circular Dichroism. J Bioanal Biomed 9: 107-113. doi:10.4172/1948-593X.1000162

15. Li D, Zhang T, Xu C, Ji B (2011) Effect of pH on the interaction of baicalein with lysozyme by spectroscopic approaches. J Photochem Photobiol B 104: 414-424.

16. Li SH, Li D (2011) Investigation on the pH-dependent binding of benzocaine and lysozyme by fluorescence and absorbance. Spectrochim Acta A Mol Biomol Spectrosc 82: 396-405.

17. Li D, Hong D, Guo H, Chen J, Ji B (2012) Probing the influences of urea on the interaction of sinomenine with human serum albumin by steady-state fluorescence. J Photochem Photobiol B 117: 126-131.

18. Li D, Wang Y, Chen J, Ji B (2011) Characterization of the interaction between farrerol and bovine serum albumin by fluorescence and circular dichroism. Spectrochim Acta A Mol Biomol Spectrosc 79: 680-686.

19. Li DJ, Zhang T, Xu C, Ji B (2011) Effect of pH on the interaction of vitamin B12 with bovine serum albumin by spectroscopic approaches. Spectrochim Acta A Mol Biomol Spectrosc 83: 598-608.

20. Li D, Zhu M, Xu C, Chen J, Ji B (2011) The effect of $\mathrm{Cu}^{2+}$ or $\mathrm{Fe}^{3+}$ on the noncovalent binding of rutin with bovine serum albumin by spectroscopic analysis. Spectrochim Acta A Mol Biomol Spectrosc 78: 74-79.

21. Zhang T, Li D (2013) Influences of urea and pH on the interaction of cinchonidine with bovine serum albumin by steady state fluorescence spectroscopy. Spectrochim Acta A Mol Biomol Spectrosc 112: 15-20.

22. Li D, Ji B, Jin J (2008) Spectrophotometric studies on the binding of Vitamin C to lysozyme and bovine liver catalase. J Lumin 128: 1399-1406.

23. Li D, Cao X, Ji B (2010) Spectrophotometric studies on the interaction between myricetin and lysozyme in the absence or presence of $\mathrm{Cu}^{2+}$ or $\mathrm{Fe}^{3+}$. $\mathrm{J}$ Lumin 130: 1893-1900.

24. Yu Z, Li D, Ji B, Chen J (2008) Characterization of the binding of nevadensin to bovine serum albumin by optical spectroscopic technique. J Mol Struct 889 : 422-428.

25. Sulkowska A (2002) Interaction of drugs with bovine and human serum albumin. J Mol Struct 614: 227-232.

26. Xie MX, Long M, Liu Y, Qin C, Wang YD (2006) Characterization of the interaction between human serum albumin and morin. Biochim Biophys Acta 1760: 1184-1191.

27. Zhang X, Zhai H, Gao R, Zhang J, Zhang Y, et al. (2014) Study on the interaction between 4-thio-5-methyluridine and human serum albumin by spectroscopy and molecular modeling. Spectrochim Acta A Mol Biomol Spectrosc 121: 724-731.

28. Fu L, Liu XF, Zhou QX, Zhang JX, Dong JY, et al. (2014) Characterization of the interactions of human serum albumin (HSA), gatifloxacin, and metronidazole using spectroscopic and electrochemical methods. J Lumin 149: 208-214.

29. Shahabadi N, Hadidi S (2014) Molecular modeling and spectroscopic studies on the interaction of the chiral drug venlafaxine hydrochloride with bovine serum albumin. Spectrochim Acta A Mol Biomol Spectrosc 122: 100-106.

30. Bi S, Pang B, Wang T, Zhao T, Yu W (2014) Investigation on the interactions of clenbuterol to bovine serum albumin and lysozyme by molecular fluorescence technique. Spectrochim Acta A Mol Biomol Spectrosc 120: 456-461.

31. Shi JH, Wang J, Zhu YY, Chen J (2014) Characterization of interaction between isoliquiritigenin and bovine serum albumin: Spectroscopic and molecular docking methods. J Lumin 145: 643-650.

32. Cahyana Y, Gordon MH (2013) Interaction of anthocyanins with human serum albumin: Influence of $\mathrm{pH}$ and chemical structure on binding. Food Chem 141: 2278-2285.

33. Yao Q, Yu X, Zheng T, Liu H, Yang Y, et al. (2013) Spectroscopic studies on the interaction of carteolol hydrochloride and urea-induced bovine serum albumin. Spectrochim Acta A Mol Biomol Spectrosc 113: 447-451.

34. Hierrezuelo JM, Nieto-Ortega B, Rui CC (2014) Assessing the interaction of Hecameg ${ }^{\circledR}$ with Bovine Serum Albumin and its effect on protein conformation: A spectroscopic study. J Lumin 147: 15-22.
35. Li J, Wang S (2013) Molecular spectroscopic on interaction between Methy hesperidin and Buman serum albumin. Spectrochim Acta A Mol Biomol Spectrosc 102: 200-204.

36. Kaboudin B, Moradi K, Faghihi MR, Mohammadi F (2013) The fluorescence spectroscopic studies on the interaction of novel aminophosphinic acids with bovine serum albumin. J Lumin 139: 104-112.

37. Wang J, Li S, Peng X, Yu Q, Bian H, et al. (2013) Multi-spectroscopic studies on the interaction of human serum albumin with astilbin: binding characteristics and structural analysis. J Lumin 136: 422-429.

38. Lakowicz JR (2006) Principles of Fluorescence Spectroscopy. Springer, New York, USA.

39. Qin C, Xie MX, Liu Y (2007) Characterization of the myricetin-human serum albumin complex by spectroscopic and molecular modeling approaches. Biomacromolecules 8: 2182-2189.

40. Ackermann T (1987) KA Connors: Binding constants-the measurement of molecular complex stability, John Wiley \& Sons, New York, Chichester, Brisbane, Toronto, Singapore 1987. 411 Seiten, Preis: $£$ 64.15 91: 987-1398.

41. Xie MX, Xu XY, Wang YD (2005) Interaction between hesperetin and human serum albumin revealed by spectroscopic methods. Biochim Biophys Acta 1724: $215-224$.

42. Johansson JS (1997) Binding of the volatile anesthetic chloroform to albumin demonstrated using tryptophan fluorescence quenching. J Biol Chem 272 17961-17965.

43. Chen GZ, Huang XZ, Zheng Z, Xu JG, Wang ZB (1990) Fluorescence Analytical Method ( $2^{\text {nd }}$ edn. $)$. Science Press, Beijing, China, p: 117.

44. Abert WC, Gregory WM, Allan GS (1993) The binding interaction of Coomassie blue with proteins. Anal Biochem 213: 407-413.

45. Ashoka S, Seetharamappa J, Kandagal PB, Shaikh SMT(2006) Investigation of the interaction between trazodone hydrochloride and bovine serum albumin $\mathrm{J}$ Lumin 121: 179-186.

46. Weber G (1961) Enumeration of Components in Complex Systems by Fluorescence Spectrophotometry. Nature 190: 27-29.

47. He W, Li Y, Xue C, Hu Z, Chen X, et al. (2005) Effect of Chinese medicine alpinetin on the structure of human serum albumin. Bioorg Med Chem 13 1837-1845.

48. Yang P, Gao F (2002) The Principle of Bioinorganic Chemistry. Science Press Beijing, China p: 349 .

49. Bos OJ, Fischer MJ, Wilting J, Janssen LH (1989) Mechanism by which warfarin binds to human serum albumin: Stopped-flow kinetic experiments with two large fragments of albumin. Biochem Pharmacol 38: 1979-1984.

50. Bos OJ, Fischer MJ, Wilting J, Janssen LH (1988) Drug-binding and othe physicochemical properties of a large tryptic and a large peptic fragment of human serum albumin. Biochim Biophys Acta 953: 37-47.

51. Sulkowska A, Rownicka J, Bojko B, Pozycka J, Zubik-Skupien I, et al. (2004) Effect of guanidine hydrochloride on bovine serum albumin complex with antithyroid drugs: fluorescence study. J Mol Struct 704: 291-295. 